\title{
Uncovering Web search strategies in South African higher education
}

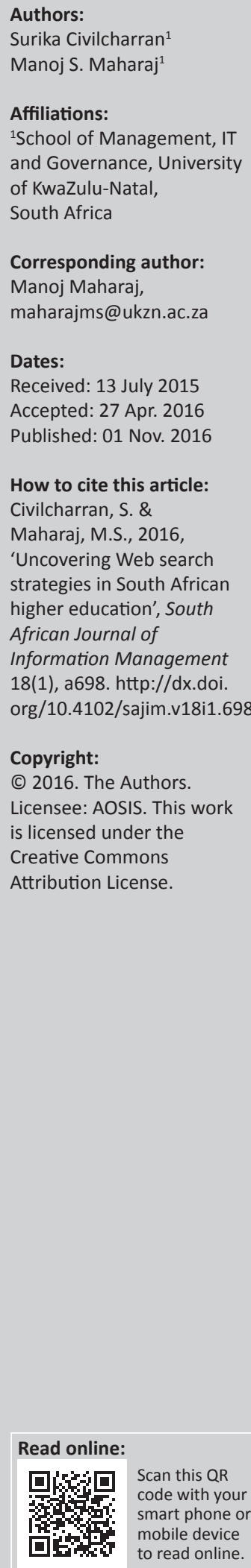

Background: In spite of the enormous amount of information available on the Web and the fact that search engines are continuously evolving to enhance the search experience, students are nevertheless faced with the difficulty of effectively retrieving information. It is, therefore, imperative for the interaction between students and search tools to be understood and search strategies to be identified, in order to promote successful information retrieval.

Objectives: This study identifies the Web search strategies used by postgraduate students and forms part of a wider study into information retrieval strategies used by postgraduate students at the University of KwaZulu-Natal (UKZN), Pietermaritzburg campus, South Africa.

Method: Largely underpinned by Thatcher's cognitive search strategies, the mixed-methods approach was utilised for this study, in which questionnaires were employed in Phase 1 and structured interviews in Phase 2. This article reports and reflects on the findings of Phase 2, which focus on identifying the Web search strategies employed by postgraduate students. The Phase 1 results were reported in Civilcharran, Hughes and Maharaj (2015).

Results: Findings reveal the Web search strategies used for academic information retrieval. In spite of easy access to the invisible Web and the advent of meta-search engines, the use of Web search engines still remains the preferred search tool. The UKZN online library databases and especially the UKZN online library, Online Public Access Catalogue system, are being underutilised.

Conclusion: Being ranked in the top three percent of the world's universities, UKZN is investing in search tools that are not being used to their full potential. This evidence suggests an urgent need for students to be trained in Web searching and to have a greater exposure to a variety of search tools. This article is intended to further contribute to the design of undergraduate training programmes in order to deal with the information retrieval frustrations of novice users.

\section{Introduction}

The first phase of this two-phase article studied the Web search tactics used in South African higher education. It identified and discussed the most commonly used Web search tactics used by postgraduate students. The findings revealed that even though a large portion of respondents reported themselves as an intermediate or expert user in retrieving information via the Web, the most frequently used tactics were those that require little cognitive effort and were presumably self-trained, through the process of trial and error. These Web search tactics are frequently related to non-academic Internet usage instead of academic usage. This turns out to be problematic, as academics demand high-quality information sources from their students.

Phase 2 builds on the findings of Phase 1 by taking the Web search tactics identified in Phase 1 and transforming these into Web search strategies. It is important to note that research has observed information-searching strategies from various levels, namely, browsing strategies and cognitive search strategies, but the classification of information-searching strategies is primarily centred on the 'query formulation and reformulation' (Kherdikar \& Kulkarni 2014; Xie 2007). In light of Web searching, researchers emphasise that the identification of various strategies for information searching is essential (Joho, Jatowt \& Blanco 2015; Xie 2007). This study therefore focuses on multiple information-seeking strategies and assists in filling the gap of a lack of empirical studies relating to several information-searching strategies in the existing body of knowledge.

To avoid confusion, the authors explain the difference between tactics and strategies in light of Web searching. According to Du and Evans (2011:299), 'Information seeking is an essential part of a scholar's work', as they are required to obtain relevant information, evaluate its quality and use it for research purposes. The quality of information is therefore strategically significant to a 
scholar's research (Du \& Evans 2011). In order to proactively manage the challenges that information retrieval brings about (via the Web), South African higher education institutions are urged to utilise the Web search strategies outlined in this study, in the form of training sessions (Kuo, Chen \& Hwang 2014).

\section{Problem statement}

The Web has become a crucial tool in industry and academia, and is being used daily to satisfy the information needs of many (Geçer 2014; Kinley et al. 2014). Graduate students were found to be savvy information searchers who required additional training in strategies and techniques to improve their ability in locating information on the Web (Blummer, Watulak \& Kenton 2012). According to Mbabu, Bertram and Varnum (2013:189), 'As students gain mastery of various subject areas, their information needs become increasingly sophisticated, as should their information seeking strategies'. It is therefore, important for Web search behaviour to be understood by information science researchers, as well as Web developers (Kinley et al. 2014). Information science researchers study the factors that shape a user's Websearching experience and Web developers use this information to improve the overall Web search experience (Kinley et al. 2014). Additionally, this study is important in guiding the design of information literacy and Web search training programs (Blummer et al. 2012).

\section{Theoretical underpinnings}

This study was largely based on Thatcher's (2006) cognitive search strategies and information-seeking behaviour on the Web. Thatcher's categories of search strategies were based on the work of Marchionini (1995) and Fidel et al. (1999). Thatcher (2006) used 80 participants to investigate their cognitive strategies by engaging them in participantdefined tasks as well as researcher-defined tasks to search the Web for information. He identifies several cognitive search strategies, which he categorises into: safe player strategy, parallel player strategy, link-dependent strategy, to-the-point strategy, known address strategy, sequential player strategy, deductive reasoning strategy and secondary search strategies, as discussed below.

\section{Safe player strategies}

These strategies are familiar to the searcher and possibly worked in previous searches. The idea behind this strategy is for the search to remain in a familiar environment and not to move far into 'unknown' search domain. Thatcher (2006) further categorises four types of safe player strategies:

\section{Broad first}

Searchers would use a familiar search engine and would type the Web address if they remembered. If they did not remember the Web address, they would search using one or more universal search terms outlined in the search task.

\section{Search engine narrowing down}

A searcher selected a search engine based on its perceived or known attributes or indicated a search engine's subject categories that would help in limiting the search domain.

\section{Search engine player strategy}

Various search engines were used to search distinct segments of the Web using the same search criteria and/or terms that were based on the capabilities of those search engines used. Some searchers would use meta-search engines instead.

\section{Known address search domain}

Searchers go to a familiar Website which may be used as a portal for the search, instead of a search engine.

\section{Parallel player strategy}

Searchers open multiple Web browser windows and conduct several searches, simultaneously using diverse search strategies for each Web browser.

\section{Link-dependent strategy}

Searchers use the hyperlinks on a homepage to travel to other Webpages in search for the required information.

\section{To-the-point strategy}

Searchers initially use relatively precise search terms with the intent of obtaining the precise answer.

\section{Known address strategy}

Searchers move straight to a Website that they have experience with and where they believe is a good possibility to find the required results.

\section{Sequential player strategy}

The searcher moves rapidly from to-the-point strategy to the safe player strategy, or vice versa.

\section{Deductive reasoning strategy}

Searchers use search terms that may seem irrelevant to the search task. These search terms typically seem illogical, but closer scrutiny of the rationale behind these search terms generally reveals that searchers were drawing on an analytical method to the search task.

\section{Secondary search strategies}

The following strategies do not require a predetermined starting point:

\section{Virtual tourist strategy}

The searcher pursues an established set of links to resolve the search task. 


\section{Parallel hub-and-spoke strategy}

The searcher opens every search result in a different browser window, rather than revisiting the search engine's results page.

Thatcher also found that expert searchers tended to frequently use 'Parallel player' and 'Parallel hub-and-spoke' strategies and rarely used 'Known address' and 'Known address search domain strategies' (Gabbard et al. 2014). In contrast, he found that novice searchers typically used strategies, such as 'Broad first', 'Virtual tourist', 'Sequential player', 'Link-dependent', 'Search engine narrowing', and 'To-the-point strategies', which involved minimal cognitive effort (Gabbard et al. 2014).

\section{Search tactics versus search strategies}

Thatcher (2006) points out that there are various definitions of the term 'strategy' in relation to Web searching and studies have frequently confused a search task with a search strategy. According to Hung et al. (2008), a tactic is a specific manoeuvre carried-out to advance a strategy. They further explain that these tactics are typically used to narrow the search results and / or enhance the precision and recall of a search. However, Wildemuth (2004:246) claims that a search tactic may be 'a set of moves that are temporally and semantically related'. For the purpose of this study, a tactic is regarded as a combination of moves.

Search strategies can be perceived as the preparation for implementing search tasks, which involve several search stratagems and tactics (Kriewel \& Fuhr 2010). Bates (1979) defines a search strategy as an overall plan for the entire search. Marchionini (1995) in Thatcher (2006:1055) defines strategies as 'generalised approaches to particular information seeking problems'. Based on these definitions, we will regard a search strategy as a combination of search tactics.

\section{Web search strategies}

It can be argued that when students begin searching the Web, they do not actually think through the information search process (Gross, Armstrong \& Latham 2012; Weare 2010). However, four key questions should be answered before embarking on the search, namely, 'Is the open Web the right tool?', 'What type of sources are likely to contain the information I need?', 'Where am I likely to find this information?' and 'What terms are likely to appear on the page I am looking for?' (Weare 2010:56). Weare explains that in some instances, the approach taken to search the Web may be inappropriate, while in other instances the problem may be the tool chosen. He thus maintains that a more efficient approach may prove to be the use of a subject-specific search tool. Several models and theories have suggested that knowledge, or experience, with systems play a crucial role in establishing the search strategy employed, in addition to the effectiveness of the search (Thatcher 2008).

Table 1 provides a list of studies with regard to Web-searching strategies, the methods used by the researchers, the sample size for each study and the strategies identified by each researcher.

\section{Research design}

The target population for this study was postgraduate students of the University of KwaZulu-Natal (UKZN), Pietermaritzburg campus, South Africa. This mixed method study involved two phases. The procedure for Phase 1 is discussed in Civilcharran, Hughes and Maharaj (2015). Researchers have used multiple data-gathering techniques (i.e. quantitative and qualitative in a single study) to

TABLE 1: Studies investigating Web-searching strategies.

\begin{tabular}{lll}
\hline Author and perspective & Study methods & Sample size technique (participants) \\
\hline Ho et al. (2012) & Questionnaires, videotapes and interviews & $\begin{array}{l}N=30 \\
\text { Theoretical sampling } \\
\text { (University students) }\end{array}$ \\
Du and Evans (2011) & Search logs, questionnaires and interviews & $\begin{array}{l}N=42 \\
\text { Unspecified } \\
\text { (Postgraduate students) }\end{array}$
\end{tabular}

\begin{tabular}{|c|c|c|c|}
\hline Author and perspective & Study methods & Sample size technique (participants) & Strategies \\
\hline Ho et al. (2012) & Questionnaires, videotapes and interviews & $\begin{array}{l}N=30 \\
\text { Theoretical sampling } \\
\text { (University students) }\end{array}$ & $\begin{array}{l}\text { Search engines, keywords, landmark websites, } \\
\text { comparing search results, browsing webpages }\end{array}$ \\
\hline Du and Evans (2011) & Search logs, questionnaires and interviews & $\begin{array}{l}N=42 \\
\text { Unspecified } \\
\text { (Postgraduate students) }\end{array}$ & $\begin{array}{l}\text { Interaction with multiple search systems, } \\
\text { exploration from popular search engines, usage } \\
\text { of basic search function, multi-tasking } \\
\text { reformulation, parallel reformulation and } \\
\text { recurrent reformulation }\end{array}$ \\
\hline Tseng et al. (2009) & $\begin{array}{l}\text { Transaction log data of a meta-search engine } \\
\text { (i.e. Dogpile) }\end{array}$ & $\begin{array}{l}N=116,466 \\
\text { Unspecified } \\
\text { (Total population in log file) }\end{array}$ & $\begin{array}{l}\text { Query reformulation (generalised, specified, } \\
\text { dynamic, constant) }\end{array}$ \\
\hline Tseng and $\mathrm{Wu}(2008)$ & $\begin{array}{l}\text { Questionnaire, experimental observation, } \\
\text { and interviews }\end{array}$ & $\begin{array}{l}N=34 \\
\text { Purposive sampling } \\
\text { (Patent engineers) }\end{array}$ & $\begin{array}{l}\text { Keywords, related terms, broader terms and } \\
\text { then narrower terms }\end{array}$ \\
\hline $\begin{array}{l}\text { Hung et al. (2008) (Cognitive } \\
\text { Scientific) }\end{array}$ & $\begin{array}{l}\text { Observational data, client-side log-files and } \\
\text { information science literature }\end{array}$ & $\begin{array}{l}\text { Unspecified } \\
\text { Unspecified } \\
\text { (Health science librarians) }\end{array}$ & $\begin{array}{l}\text { Grand strategy, strategy, tactics, operations, } \\
\text { assessment }\end{array}$ \\
\hline Bhavnani et al. (2006) & Experimental and questionnaires & $\begin{array}{l}N=59 \\
\text { Convenience sampling (Undergraduate students) }\end{array}$ & $\begin{array}{l}\text { Domain portal called the Strategy Hub based on } \\
\text { search procedures by experts in their field }\end{array}$ \\
\hline Thatcher (2006) (Cognitive) & $\begin{array}{l}\text { Structured interview, client-side log-files } \\
\text { and observational data }\end{array}$ & $\begin{array}{l}N=80 \\
\text { Snowball sampling } \\
\text { (University students, } \\
\text { academic staff, school children, professionals) }\end{array}$ & $\begin{array}{l}\text { Cognitive search, safe player, parallel player, } \\
\text { link-dependant, to-the-point, known address, } \\
\text { sequential player, deductive reasoning and } \\
\text { secondary search strategies }\end{array}$ \\
\hline Nachmias and Gilad (2002) & Client-side log-files and questionnaire & $\begin{array}{l}N=54 \\
\text { Unspecified } \\
\text { (Master's students) }\end{array}$ & $\begin{array}{l}\text { Keyword search, wide search definition, complex } \\
\text { search, use of general knowledge, computer } \\
\text { convention, Boolean search, using a directory, } \\
\text { accessing a specific portal and direct typing }\end{array}$ \\
\hline Bates (1979) & $\begin{array}{l}\text { Bates experience, literature, comments from } \\
\text { her friends }\end{array}$ & $N=$ Unspecified & $\begin{array}{l}\text { Tactics - monitoring, file structure, search } \\
\text { formulation and term }\end{array}$ \\
\hline
\end{tabular}

\section{Search engines, keywords, landmark websites,} comparing search results, browsing webpages

Interaction with multiple search systems, exploration from popular search engines, usage of basic search function, multi-tasking 
corroborate their findings on Web-searching strategies (Bhavnani et al. 2006; Hung et al. 2008; Thatcher 2006; Tseng, Tjondronegoro \& Spink 2009; Tseng \& Wu 2008).

The idea behind this explanatory design is that the qualitative data assist in explaining or building upon the quantitative results (Creswell et al. 2003). Structured interviews were conducted for the qualitative component and have been successfully employed in previous research (Thatcher 2006; Tseng \& Wu 2008). Structured, face-to-face interviews were conducted with the same postgraduate students who participated in the survey (i.e. Phase 1). The interviewees were determined based on their responses in the survey. Ten respondents were identified as interview candidates, because they used the highest number of search tactics listed on the questionnaire. However, only eight respondents agreed to be interviewed. As these candidates used the highest number of tactics, they are, in the researchers' opinion, likely to have more search strategies (i.e. combination of search tactics) than those respondents that use fewer search tactics.

Interview questions were pretested to improve clarity and remove possible ambiguity. The information obtained facilitated a better understanding of information retrieval strategies used by postgraduate students. The qualitative data from the interviews was transcribed to text and stored electronically in a software package, NVivo 9. Content analysis was then used to analyse the data from the interviews, which assisted in identifying its properties systematically.

\section{Findings and discussion}

The aim of this study is to ascertain the information-seeking strategies of South African postgraduate students when searching the Web for academic information. Interviewees were required to indicate the combination(s) of tactics used in a single Web search. The analysis of the interview responses uncovered several themes. Each interviewee indicated the search strategies (i.e. combination of search tactics) used to search each information source, namely, search engines, meta-search engines, the 'invisible Web', library Online Public Access Catalogue (OPAC) system and library databases, for academic information. The tactics used by the interviewees were then categorised under Thatcher's (2006) cognitive search strategies to determine the frequently used strategies by postgraduate students.

The headings labelled 1-8 in Tables 2-6 signify each interviewee and their strategy used and may also be seen as best practices with regard to searching strategies.

\section{Web search strategies used when searching search engines}

Table 2 shows that a minimum of six search tactics were used for a single search, via a search engine. Thatcher (2008) suggests that significant cognitive resources would be required in such a case. The most frequent search tactics were the use of advanced search features (the 'search engine narrowing down' strategy), Boolean operators and multiple keywords (the 'tothe-point' strategy). In particular, the most used 'safe player' strategies for this type of searching was the 'search engine player' strategy followed by the 'search engine narrowing down' strategy. Here the interviewees selected the search engine as their choice of search tool, with the aim of 'narrowing down the search domain' (Thatcher 2006).

Thatcher (2006:1060) explains that the 'safe player' strategies focus on a participant's intention to 'remain within a safe or familiar search environment, and not to wander too far into "unknown" search territory'. On the other hand, interviewees used their favourite search engine (i.e. Google), which is a behaviour of the 'to-the-point' strategy. Typing in the Web address (the 'known address search domain' strategy) and the use of single keywords (the 'broad first' strategy) were the least used tactics, as part of their search strategies. A minimum of six tactics were used to form a single search strategy, and one interviewee even went up to 10 tactics.

\section{Web search strategies used when searching meta-search engines}

In Table 3, the most commonly used search tactic was the use of Boolean operators (the 'to-the-point' strategy), followed by the opening of multiple Web browser tabs (the 'parallel player'),

TABLE 2: Web search strategies using search engines.

\begin{tabular}{|c|c|c|c|c|c|c|c|c|c|}
\hline Search engines tactics & 1 & 2 & 3 & 4 & 5 & 6 & 7 & 8 & Total \\
\hline Modify query to find more accurate information & - & - & 1 & 1 & 1 & - & 1 & - & 4 \\
\hline Open multiple tabs & - & 1 & - & 1 & 1 & 1 & 1 & 1 & 6 \\
\hline Open multiple windows & 1 & 1 & - & 1 & 1 & - & - & - & 4 \\
\hline Search for specific phrases using quotation marks & - & - & 1 & 1 & 1 & 1 & - & - & 4 \\
\hline Type in the Web address & - & - & - & - & - & - & - & 1 & 1 \\
\hline Use advanced search features & 1 & 1 & 1 & - & 1 & 1 & 1 & 1 & 7 \\
\hline Use multiple keywords & 1 & 1 & 1 & 1 & - & 1 & 1 & 1 & 7 \\
\hline Use multiple search engines & - & - & - & - & - & 1 & 1 & 1 & 3 \\
\hline Use proximity searching & - & 1 & - & - & 1 & - & 1 & 1 & 4 \\
\hline Use single keywords & - & - & 1 & - & - & - & - & - & 1 \\
\hline Use synonyms & - & - & 1 & 1 & 1 & - & 1 & 1 & 5 \\
\hline Use the find feature & 1 & - & - & - & 1 & - & - & 1 & 3 \\
\hline Use truncation and wildcards & 1 & 1 & 1 & - & 1 & 1 & 1 & - & 6 \\
\hline
\end{tabular}


the use of advanced search features (the 'search engine narrowing down' strategy), the use of multiple keywords and truncation (the 'to-the-point' strategy). According to Thatcher (2006), 'parallel player' strategies focus on when the participant deliberately opens multiple browser windows to perform different searches simultaneously. Thatcher (2006:1062) further explains that these participants typically used a different strategy within each browser window.

Thatcher (2006) describes the 'to-the-point' strategy, where participants used exact words or phrases to encapsulate the search task, and in some instances employed Boolean logic terms to 'narrow the search domain or to exclude certain search domains'. Similar to the findings of Thatcher (2006), the least used tactics for meta-search engines were typing in the Web address (the 'known address search domain' strategy) and the use of single keywords (the 'broad first' strategy). The highest number of tactics used to form a single search strategy is 10 while the least is 5 .

\section{Web search strategies used when searching the 'invisible Web'}

Table 4 shows the most commonly used tactic is the use of multiple keywords and the opening of multiple Web browser tabs (the 'parallel player' strategy), while the least used tactic was typing in the Web address (the 'known address search domain' strategy) and the use of multiple search engines (the 'search engine player' strategy). Similar to the findings of this study, Guo (2013) (in Gabbard et al. 2014) found that onethird of the students $(34.78 \%)$ used only Websites they are familiar with. The highest number of tactics combined to form a single strategy is 10 while the least is 3 .

\section{Web search strategies used when searching the University of KwaZulu-Natal library Online Public Access Catalogue system}

The OPAC is a library system used by UKZN students for accessing the library catalogue when searching for resources in campus libraries. In Table 5, the majority of the interviewees used advanced search features (the 'search engine narrowing down' strategy), followed by the use of multiple keywords (the 'to-the-point' strategy), while the least used tactic is the use of single keywords (the 'broad first' strategy). The highest number of tactics used to form a single strategy is nine while the least is three.

\section{Web search strategies used when using the University of KwaZulu-Natal online library databases}

Table 6 shows the various Web search strategies used when interviewees search for information using the UKZN online library databases. The most commonly used search tactics

TABLE 3: Web search strategies using meta-search engines.

\begin{tabular}{|c|c|c|c|c|c|c|c|c|c|}
\hline Meta-search engines tactics & 1 & 2 & 3 & 4 & 5 & 6 & 7 & 8 & Total \\
\hline Modify query to find more accurate information & - & - & 1 & 1 & 1 & - & 1 & - & 4 \\
\hline Open multiple tabs & - & 1 & - & 1 & 1 & 1 & 1 & 1 & 6 \\
\hline Open multiple windows & 1 & - & - & 1 & 1 & - & - & - & 3 \\
\hline Search for specific phrases using quotation marks & - & - & 1 & 1 & 1 & 1 & - & - & 4 \\
\hline Type in the Web address & - & - & - & - & - & - & - & 1 & 1 \\
\hline Use advanced search features & 1 & - & 1 & - & 1 & 1 & 1 & 1 & 6 \\
\hline Use Boolean operators & 1 & 1 & 1 & 1 & 1 & 1 & - & 1 & 7 \\
\hline Use multiple keywords & 1 & 1 & - & 1 & - & 1 & 1 & 1 & 6 \\
\hline Use multiple search engines & - & - & - & - & - & 1 & - & - & 1 \\
\hline Use proximity searching & - & 1 & - & - & 1 & - & 1 & 1 & 4 \\
\hline Use single keywords & - & - & 1 & - & - & - & - & - & 1 \\
\hline Use synonyms & - & - & 1 & 1 & 1 & - & 1 & 1 & 5 \\
\hline Use the find feature & 1 & - & - & - & 1 & - & - & 1 & 3 \\
\hline Use truncation and wildcards & 1 & 1 & 1 & - & 1 & 1 & 1 & - & 6 \\
\hline
\end{tabular}

TABLE 4: Web search strategies using the 'invisible Web'.

\begin{tabular}{|c|c|c|c|c|c|c|c|c|c|}
\hline 'Invisible Web' tactics & 1 & 2 & 3 & 4 & 5 & 6 & 7 & 8 & Total \\
\hline Modify query to find more accurate information & 1 & - & 1 & - & 1 & - & 1 & - & 4 \\
\hline Open multiple tabs & - & 1 & - & 1 & 1 & 1 & 1 & 1 & 6 \\
\hline Open multiple windows & 1 & - & - & 1 & 1 & - & - & - & 3 \\
\hline Search for specific phrases using quotation marks & - & - & - & - & 1 & 1 & - & - & 2 \\
\hline Type in the Web address & - & - & - & - & - & - & - & 1 & 1 \\
\hline Use advanced search features & - & - & 1 & - & 1 & 1 & 1 & 1 & 5 \\
\hline Use Boolean operators & 1 & 1 & - & - & 1 & 1 & - & 1 & 5 \\
\hline Use multiple keywords & 1 & 1 & 1 & 1 & - & 1 & 1 & 1 & 7 \\
\hline Use multiple search engines & - & - & - & - & - & 1 & - & - & 1 \\
\hline Use proximity searching & - & 1 & - & - & 1 & - & 1 & 1 & 4 \\
\hline Use synonyms & 1 & - & - & 1 & 1 & - & 1 & 1 & 5 \\
\hline Use the find feature & 1 & - & - & - & 1 & - & - & 1 & 3 \\
\hline Use truncation and wildcards & 1 & 1 & - & - & 1 & 1 & 1 & - & 5 \\
\hline Total tactics used per interviewee & 7 & 5 & 3 & 4 & 10 & 7 & 7 & 8 & - \\
\hline
\end{tabular}


TABLE 5: Web search strategies using the University of KwaZulu-Natal library Online Public Access Catalogue system.

\begin{tabular}{|c|c|c|c|c|c|c|c|c|c|}
\hline $\begin{array}{l}\text { University of KwaZulu-Natal library Online Public Access Catalogue } \\
\text { catalogue system tactics }\end{array}$ & 1 & 2 & 3 & 4 & 5 & 6 & 7 & 8 & Total \\
\hline Modify query to find more accurate information & - & - & 1 & - & 1 & - & 1 & - & 3 \\
\hline Open multiple tabs & - & 1 & - & 1 & 1 & - & 1 & 1 & 5 \\
\hline Open multiple windows & 1 & - & - & 1 & 1 & - & - & - & 3 \\
\hline Search for specific phrases using quotation marks & - & - & 1 & 1 & 1 & 1 & - & - & 4 \\
\hline Use advanced search features & 1 & 1 & 1 & - & 1 & 1 & 1 & 1 & 7 \\
\hline Use Boolean operators & 1 & - & 1 & - & 1 & - & - & 1 & 4 \\
\hline Use multiple keywords & 1 & 1 & - & 1 & - & 1 & 1 & 1 & 6 \\
\hline Use proximity searching & - & - & - & - & 1 & - & 1 & 1 & 3 \\
\hline Use single keywords & - & - & 1 & - & - & - & - & - & 1 \\
\hline Use synonyms & - & - & 1 & 1 & 1 & - & 1 & 1 & 5 \\
\hline Use the find feature & - & - & - & - & 1 & - & - & 1 & 2 \\
\hline Use truncation and wildcards & - & - & 1 & - & - & - & 1 & - & 2 \\
\hline Total tactics used per interviewee & 4 & 3 & 7 & 5 & 9 & 3 & 7 & 7 & - \\
\hline
\end{tabular}

TABLE 6: Web search strategies using the University of KwaZulu-Natal online library databases.

\begin{tabular}{|c|c|c|c|c|c|c|c|c|c|}
\hline University of KwaZulu-Natal online library databases tactics & 1 & 2 & 3 & 4 & 5 & 6 & 7 & 8 & Total \\
\hline Modify query to find more accurate information & - & - & 1 & - & 1 & - & 1 & - & 3 \\
\hline Open multiple tabs & - & - & - & 1 & 1 & 1 & 1 & 1 & 5 \\
\hline Open multiple windows & 1 & - & - & 1 & 1 & - & - & - & 3 \\
\hline Search for specific phrases using quotation marks & - & - & 1 & 1 & 1 & 1 & - & - & 4 \\
\hline Use advanced search features & - & - & 1 & - & 1 & 1 & 1 & 1 & 5 \\
\hline Use Boolean operators & - & - & 1 & - & 1 & 1 & - & 1 & 4 \\
\hline Use proximity searching & - & - & - & - & 1 & - & 1 & 1 & 3 \\
\hline Use single keywords & - & - & 1 & - & - & - & - & - & 1 \\
\hline Use synonyms & - & - & 1 & 1 & 1 & - & 1 & 1 & 5 \\
\hline Use the find feature & 1 & - & - & - & 1 & - & - & 1 & 3 \\
\hline Use truncation and wildcards & - & - & 1 & - & 1 & 1 & 1 & - & 4 \\
\hline Total tactics used per interviewee & 2 & 0 & 8 & 5 & 10 & 6 & 7 & 7 & - \\
\hline
\end{tabular}

were the opening of multiple Web browser tabs ('parallel player'), the use of advanced search features (the 'search engine narrowing down' strategy), the use of multiple keywords (the 'To-the-point' strategy) and the use of synonyms. The least used tactics is the use of single keywords. The highest number of tactics used to form a single strategy is 10 and the least is 2 . The second interviewee does not use the UKZN online library databases.

According to Mbabu et al. (2013:189), 'Libraries have long advocated for use of scholarly databases because of their richness in academic material and scarcity of advertisements'. Guo (2013) (in Gabbard et al. 2014) found most students used the library databases (88.41\%) and Web search engines (78.26\%) when selecting a search tool. However, this is contrary to the findings of this study, where most interviewees rarely used the online library databases, as they preferred to use a search engine, and one interviewee did not use it at all. This is a disturbing finding, as a considerable amount of money is spent by the university each year on these online databases, which are clearly being underutilised. As academic library expenditures on journal subscriptions and electronic databases continue to increase, united with students' preference for Webbased resources, it is crucial to investigate the use of online library resources for academic libraries (Miller 2014).

Colón-Aguirre and Fleming-May (2012) explain a few reasons why students did not prefer searching the library databases and the OPAC system. They found that students expressed frustration to a certain degree with the procedure of interacting with database search platforms and with identifying suitable electronic resources amid a massive collection of databases. Postgraduate students in this study could also be facing the same frustrations, explaining their preference for search engines. In light of this, academic librarians should target continuous information literacy progress within the disciplinary curriculum, for all levels of study, inspiring students to employ academic library resources essential for profound engagement within every academic discipline (Miller 2014).

\section{The total Web search tactics used for all search tools}

This section provides an overview of which search tactics are the most popular, so that a searcher attempting to use the tactics above will have an idea of which tactics may work better. Tseng and Wu (2008) found that the most frequent approach was the use of keywords at the initial stage of the search process, followed by the use of related words, then the use of broader terms and finally the use of narrower terms. The top three Web search tactics are the use of multiple keywords (the 'to-the-point' strategy) and the use of advanced search features (the 'search engine narrowing down' strategy), followed by the opening of multiple Web browser tabs ( 'parallel player').

Aula, Jhaveri and Käki (2005) suggests that multiple tabs are used more frequently than multiple windows and may be 
due to the disadvantage of multiple browsers cluttering the workspace. The reason for not using multiple windows, as Thatcher (2008) suggests is that considerable cognitive resources are required, more attention is required when searching than when using one Web browser at a time. In addition, users will have to constantly remind themselves of each search and its progress (Thatcher 2008). Aula et al. (2005) also points out that some strategies recommended in previous studies are not that important, such as the use of URLs on a Webpage. This may be the reason why typing in the Web address was one of the least used Web search tactics. Contrary to the findings of this study, Markey (2007) reviewed 25 years of published research findings on information retrieval on the Web and found that Boolean searching was not as popular in the past, as only $20 \%$ of queries included Boolean operators. This study shows that this trend seems to be changing, at least in the UKZN, Pietermaritzburg campus, postgraduate context.

\section{Reasons for preferred Web search strategies when searching for academic information}

Most interviewees explained the reason they preferred the search strategies currently used is that they believe these strategies to be effective and efficient in returning precise search results. Other reasons were that these strategies were the only ones they knew and believed that these with these strategies retrieves more precise information, which are ordered by relevance. One interviewee stated that these combinations made it easier to get the latest articles and dissertations in PDF format, especially when the UKZN library OPAC catalogue system and the UKZN online library databases were used. She explained that her strategy acquired all the necessary PDF files without her opening many Web sites. Another interviewee pointed out that the UKZN library OPAC catalogue system, and the library database mainly deal with scholarly works, so these search tools should be used when searching for academic information rather than using commercial search engines.

\section{The criteria used to determine if a Web search was successful}

Two interviewees indicated that they usually read the abstract, while one of them goes further to look for files in PDF format, reads the heading and finally the abstract. A few interviewees considered a search to be successful if between $50 \%$ and $70 \%$ of the links were relevant. Other criteria involved reading the information under each link on the results pages, to see how current the material was and if found within an hour, then the search was considered successful. Cummins (2001) suggests that the most fundamental aspects of Web searching are not only to develop a good Web-searching strategy by asking specific questions but also to follow up by thinking critically in addition to evaluating the search results.

\section{Limitations}

Firstly, a generalisation outside this university is uncertain. The researchers investigated the Web search strategies of postgraduate students at a South African university, namely, University of KwaZulu-Natal. Financial and time constraints implied that other universities in South Africa could not form part of the study. Hence, the study was constrained to the university under consideration. A study of several universities would provide a more comprehensive representation regarding the Web search strategies of South African students in higher education. Nevertheless, studying only one university warranted adequate time to the case. In addition, the mixedmethods approach utilised in Phase 1, as well as in this study has broadened the analysis parameters and provided an increased understanding of Web search strategies. Secondly, this study was carried out on postgraduate students, which may restrict the generalisability of the results to other tertiary levels.

\section{Conclusion and future research}

This article has presented the findings of Phase 2 of a wider study into the Web search behaviour of postgraduate students at UKZN, Pietermaritzburg campus, South Africa. In Phase 1, many respondents indicated their lack of knowledge on several search tools and tactics. In light of this, each Web search strategy may be tried by a novice Web searcher to determine the strategy that works best for him/her as these strategies (i.e. combination of tactics) are heuristic (Bates 1979). One could possibly further refine the search strategy adopted to retrieve information even more effectively. This way, the inexperienced user increases his/her knowledge of the various search tactics available, thereby moving from being a novice searcher to becoming an intermediate searcher and possibly even an expert searcher over time.

The findings revealed that several search tactics were used in combination when searching for information. And while some strategies worked for one search tool, they did not necessarily work for another. In addition, no two interviewees used exactly the same combination of tactics to form a single search strategy. When searching for academic information, the search engine was still the search tool of choice. Nazim (2008) had a similar finding. The top three Web search tactics employed by the interviewees are the use of multiple keywords (the 'to-the-point' strategy), the use of advanced search features (the 'search engine narrowing down' strategy) and the opening of multiple Web browser tabs ('parallel player'). In contrast, the use of multiple search engines (the 'search engine player' strategy), single keywords (the 'broad first' strategy) and typing in the Web address (the 'known address search domain' strategy) were the least used search tactics. Prior Web experience, in addition to knowledge on the subject matter, performs a vital part in establishing the searching strategies one would use (Ho, Lin \& Chen 2012; Thatcher 2006).

Bates' (1979) model of information search tactics was created for both manual and online searching. In their future work, the authors will adapt Bates' model to suit Web searching just as it was adapted to suit the online environment. This adapted model will have the potential to assist future 
researchers in the field and expose novice searchers on the various Web search strategies that are available. Additionally, academic institutions may use the adapted model when developing training materials.

Research is a core component of postgraduate studies. It is therefore imperative to understand what percentage of students is impacted by the large expenditure on online library resources. It is also important to investigate the extent to which these online library databases are being underutilised and the reason behind this phenomenon. Academic librarians need to find new techniques of inspiring students in higher education to utilise the online library resources, in order to justify the massive expenditure on these resources.

\section{Acknowledgements Competing interests}

The authors declare that they have no financial or personal relationships which may have inappropriately influenced them in writing this article.

\section{Authors' contributions}

This article, resulted from the Masters research of S.C. and M.S.M. provided editorial oversight and final approval.

\section{References}

Aula, A., Jhaveri, N. \& Käki, M., 2005, 'Information search and re-access strategies of experienced Web users', Paper presented at the 14th International Conference on World Wide Web, Nippon Convention Center (Makuhari Messe), Chiba, Japan, 10-14th May.

Bates, M.J., 1979, 'Information search tactics', Journal of the American Society for Information Science 30(4), 205-214. http://dx.doi.org/10.1002/asi.4630300406

Bhavnani, S.K., Bichakjian, C.K., Johnson, T.M., Little, R.J., Peck, F.A., Schwartz, J.L., et al., 2006, 'Strategy hubs: Domain portals to help find comprehensive information', Journal of the American Society for Information Science and Technology 57(1), 4-24. http://dx.doi.org/10.1002/asi.20238

Blummer, B., Watulak, S.L. \& Kenton, J., 2012, 'The research experience for education graduate students: A phenomenographic study', Internet Reference Services Quarterly 17(3-4), 117-146. http://dx.doi.org/10.1080/10875301.2012.747462

Civilcharran, S., Hughes, M. \& Maharaj, M.S., 2015, 'Uncovering Web search tactics in South African higher education', South African Journal of Information Management 17(1), Art. \#644, 8 pages. http://dx.doi.org/10.4102/sajim.v17i1.644

Colón-Aguirre, M. \& Fleming-May, R.A., 2012, “"You just type in what you are looking for": Undergraduates' use of library resources vs. Wikipedia', The Journal of Academic Librarianship 38(6), 391-399. http://dx.doi.org/10.1016/j.acalib.2012.09.013

Creswell, J.W., Plano Clark, V.L., Gutmann, M. \& Hanson, W., 2003, 'Advanced mixed methods research designs', in A. Tashakkori \& C. Teddlie (eds.), Handbook of mixed methods in social and behavioural research, Sage, Thousand Oaks, CA.

Cummins, R., 2001, Choosing the right tool for the job: Searchbots, The Technology Source Archives, viewed 13 July 2015, from http://technologysource.org/article/ choosing_the_right_tool_for_the_job/

Du, J.T. \& Evans, N., 2011, 'Academic users' information searching on research topics: Characteristics of research tasks and search strategies', The Journal of Academic Librarianship 37(4), 299-306. http://dx.doi.org/10.1016/j.acalib. 2011.04.003

Fidel, R., Davies, R.K., Douglass, M.H., Holder, J.K., Hopkins, C.J., Kushner, E.J. et al., 1999, 'A visit to the information mall: Web searching behaviour of high school students', Journal of the American Society for Information Science 50 24-37. http://dx.doi.org/10.1002/(SICI)1097-4571(1999)50:1<24::AID-ASI5>3.0.CO
Gabbard, R., Leaming, A., Liu, Q., Lei, W. \& Guy, M., 2014, 'Uncovering the online information seeking behaviors of Chinese university students: A pilot study', Journal of East Asian Libraries 159(1), 1-22.

Geçer, A.K., 2014, 'A study on information search and commitment strategies on Web environment and Internet usage self-efficacy beliefs of university students', Turkish Online Journal of Educational Technology-TOJET 13(2), 1-17.

Gross, M., Armstrong, B. \& Latham, D., 2012, 'The Analyze, Search, Evaluate (ASE) process model: Three steps toward information literacy', Community \& Junior College Libraries 18(3-4), 103-118. http://dx.doi.org/10.1080/02763915.2012.7 80488

Guo, L., 2013, 'Research on the Information Behaviors of the Graduate Students in Engineering Colleges and Universities under Network Environment-A Case Study of Xi'an University of Science and Technology', Sci-Tech Information Development \& Economy 23(9), 130-135.

Ho, C.I., Lin, M.H. \& Chen, H.M., 2012, 'Web users' behavioural patterns of tourism information search: From online to offline', Tourism Management 33(6), 1468-1482. http://dx.doi.org/10.1016/j.tourman.2012.01.016

Hung, P.W., Johnson, S.B., Kaufman, D.R. \& Mendonça, E.A., 2008, 'A multi-level model of information seeking in the clinical domain', Journal of Biomedical Informatics 41(2), 357-370. http://dx.doi.org/10.1016/j.jbi.2007.09.005

Joho, H., Jatowt, A. \& Blanco, R., 2015, 'Temporal information searching behaviour and strategies', Information Processing \& Management 51(6), 834-850. http:// dx.doi.org/10.1016/j.ipm.2015.03.006

Kherdikar, S.K. \& Kulkarni, R., 2014, 'A novel approach for auto classification and grouping similar user query for image search', International Journal of Computer Science \& Information Technologies 5(4), 4911-4915.

Kinley, K., Tjondronegoro, D., Partridge, H. \& Edwards, S., 2014, 'Modeling users' web search behavior and their cognitive styles', Journal of the Association for Information Science and Technologys 65(6), 1107-1123. http://dx.doi.org/10.1002/ asi.23053

Kriewel, S. \& Fuhr, N., 2010, 'Evaluation of an adaptive search suggestion system', paper presented at the 32nd European Conference on Information Retrieval, The Open University, Milton Keynes, UK, 28-31st March.

Kuo, F.R., Chen, N.S. \& Hwang, G.J., 2014, 'A creative thinking approach to enhancing the web-based problem solving performance of university students', Computers \& Education 72, 220-230. http://dx.doi.org/10.1016/j.compedu.2013.11.005

Marchionini, G., 1995, Information seeking in electronic environments, Cambridge University Press, Cambridge, UK.

Markey, K., 2007, 'Twenty-five years of end-user searching, part 1: Research findings', Journal of the American Society for Information Science and Technology 58(8), 1071-1081. http://dx.doi.org/10.1002/asi.20462

Mbabu, L.G., Bertram, A. \& Varnum, K., 2013, 'Patterns of undergraduates' use of scholarly databases in a large research university', The Journal of Academic Librarianship 39(2), 189-193. http://dx.doi.org/10.1016/j.acalib.2012.10.004

Miller, K., 2014, 'Undergraduate use of library databases decreases as level of study progresses', Evidence Based Library and Information Practice 9(3), 98-100. http:// dx.doi.org/10.18438/B86K74
drog

Nachmias, R. \& Gilad, A., 2002, 'Needle in a hyperstack: Searching information on the World Wide Web', Journal of Research on Technology in Education 34(4), 475-486. http://dx.doi.org/10.1080/15391523.2002.10782362

Nazim, M., 2008, 'Information searching behavior in the internet age: A users' study of aligarh Muslim University', The International Information \& Library Review 40(1), 73-81. http://dx.doi.org/10.1080/10572317.2008.10762764

Thatcher, A., 2006, 'Information-seeking behaviours and cognitive search strategies in different search tasks on the WWW', International Journal of Industrial Ergonomics 36(1), 1055-1068. http://dx.doi.org/10.1016/j.ergon.2006.09.012

Thatcher, A., 2008, 'Web search strategies: The influence of Web experience and task type', Information Processing and Management 44(3), 1308-1329. http://dx.doi. org/10.1016/j.ipm.2007.09.004

Tseng, L.C.J., Tjondronegoro, D. \& Spink, A., 2009, 'Analyzing Web multimedia query reformulation behavior', paper presented at the 14th Australasian Document Computing Symposium, University of New South Wales, Sydney, Australia, 30th November -4 th December.

Tseng, Y.H. \& Wu, Y.J., 2008, 'A study of search tactics for patentability search - A case study on patent engineers', paper presented at the 1st ACM workshop on Patent Information Retrieval, Napa Valley Marriott Hotel \& Spa, CA, 26th - 30th October

Weare, W.H., 2010, 'Beyond Web search tips and tricks: Thinking through the search', Library Media Connection 28(4), 56-57.

Wildemuth, B.M., 2004, 'The effects of domain knowledge on search tactic formulation', Journal of the American Society for Information Science and Technology 55(3), 246-258. http://dx.doi.org/10.1002/asi.10367

Xie, H., 2007, 'Shifts in information-seeking strategies in information retrieval in the digital age: Planned-situational model', Information Research 12(4), paper colis22, viewed 20 July 2012, from http://InformationR.net/ir/12-4/colis/colis22.html 